\title{
Effects of Molar Ratio, Alkali Catalyst Concentration and Temperature on Transesterification of Jatropha Oil with Methanol under Ultrasonic Irradiation
}

\author{
Amish P. Vyas, Jaswant L. Verma, Nandula Subrahmanyam \\ Chemical Engineering Department, Nirma University, Ahmedabad, India \\ E-mail:Amish71in@yahoo.com \\ Received December 28, 2010; revised March 10, 2011; accepted March 21, 2011
}

\begin{abstract}
For transesterification of Jatropha oil into biodiesel, ultrasound assisted transesterification seems to be promising in terms of reduction in process time and stages of operation. Effects of process variables such as the catalyst loading, the molar ratio of methanol to oil, reaction temperature and the reaction time were investigated on the conversion of Jatropha oil to biodiesel. The conversion was above 93\% under the conditions of $50^{\circ} \mathrm{C}$, methanol to oil molar ratio of 9:1, reaction time $30 \mathrm{~min}$ and catalyst amount (catalyst/oil) of $1 \% \mathrm{wt} \%$. A kinetic study of transesterification of Jatropha oil based on ultrasound assisted synthesis is presented in this paper. Rate equation obtained is also presented.
\end{abstract}

Keywords: Transesterification; Ultrasound; Triglyceride; Jatropha Oil, Alkali Catalyst

\section{Introduction}

Vehicular pollutant emissions caused by the combustion of fossil fuels and crude oil price fluctuations brought into focus the need for developing alternate fuels which could create less pollution, produced from renewable feedstocks and operate without much modification in the existing design of the engine. Biodiesel (fatty acid alkyl ester) derived from transesterification of vegetable oils or an animal fat with methanol (Figure 1) is a potential substitute for petroleum based diesel fuels. Even 5\% replacement of petroleum fuel by biofuel can save a country like India Rs. 4000 crores per year in foreign exchange [1].

Government of India has already given due importance to biofuel and announced a National Biofuel policy in year 2006. The focus is on collection and distribution of renewable feedstocks for biofuel products and R \& D at pilot plant scale and later scaling upto commercial lev-

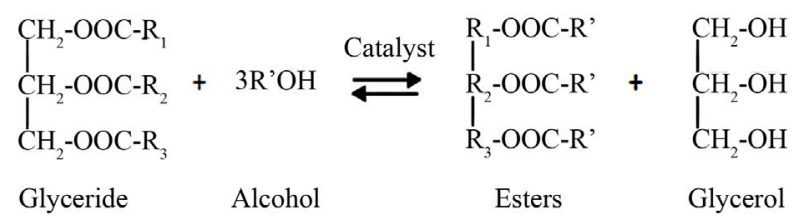

Figure 1. Transesterification of triglycerides with alcohol. el technologies for production of biodiesel using Jatropha oil and Karanja oil. At present, the biodiesel is usually produced by reacting methanol and a vegetable oil in a batch stirred tank reactor using a liquid alkaline catalyst. Ultrasound assisted transesterification process offers a number of advantages over current technology, namely the simplification of the process and downstream separation. The present study involved transesterification of Jatropha oil with methanol catalyzed by alkali catalyst. Effects of various parameters were studied.

\section{Ultrasound Technology}

Influence of ultrasound on transesterification reaction is of purely physical nature. Formation of fine emulsion between oil and alcohol due to microturbulence generated by cavitation bubbles generates enormous interfacial area, which accelerates the reaction [2]. Ultrasound is the process of propagation of the compression waves with frequencies above the range of human hearing. Ultrasound frequency ranges from $20 \mathrm{kHz}$ to $10 \mathrm{MHz}$, with associated acoustic wavelengths in liquids of about 100$0.15 \mathrm{~mm}$. These wavelengths are not on the scale of molecular dimensions. Instead, the chemical effects of ultrasound derive from several nonlinear acoustic phenomena, of which cavitation is the most important. Acoustic cavitation is the formation, growth, and implo- 
sive collapse of bubbles in a liquid irradiated with sound or ultrasound. When sound passes through a liquid, it consists of expansion (negative pressure) waves and compression (positive pressure) waves. These cause bubbles (which are filled with both solvent and solute vapour and with previously dissolved gases) to grow and recompress. Under proper conditions, acoustic cavitation can lead to implosive compression in such cavities. Such implosive bubble collapse produces intense local heating, high pressures, and very short life-times. Cavitation is an extraordinary method of concentrating the diffused energy of sound into a chemically useable form. Ultrasonication provides the mechanical energy for mixing and the required activation energy for initiating the transesterification reaction. Low-frequency ultrasonic irradiation is useful tool for emulsification of immiscible liquids. The collapse of the cavitation bubbles disrupts the phase boundary and causes emulsification, by ultrasonic jets that impinge one liquid on another [3,4].

Effect of low-frequency ultrasound was studied on the production of biodiesel via transesterification of Jatropha oil with methanol using sodium hydroxide as homogeneous catalyst.

\section{Experimental Work}

\subsection{Reagents and Materials}

Methanol (99.5\%) and sodium hydroxide (98\%) purchased from Yash Enterprise, Ahmedabad, Gujarat, India. Jatropha oil was purchased from Nidhita marketing, Ahmedabad, Gujarat, India. Properties of purchased Jatropha oil as carried out at Nirma University are shown in Table 1.

\subsection{Transesterification Procedure}

Methanol and Jatropha oil were used as a raw material to study the effect of low frequency ultrasound on biodiesel production at $303 \mathrm{~K}, 313 \mathrm{~K}, 323 \mathrm{~K}$ using molar ratio of oil to methanol ranging from $1: 3,1: 6,1: 9$ and $1: 12$, and the quantity of alkali catalyst from $0.5 \%, 1.0 \%, 1.5 \%$, and $2 \%$ (wt/wt) of the weight of Jatropha oil. The reaction mixture consists of Jatropha oil, methanol, and sodium hydroxide. Sodium hydroxide was dissolved into methanol followed by addition of Jatropha oil to the solution. Since, the Jatropha oil and methanol were not

Table 1. Properties of Jatropha oil.

\begin{tabular}{lc}
\hline \multicolumn{1}{c}{ Property } & Value \\
\hline Acid value (mg KOH/gm) & 6.171 \\
Saponification value (mg/g) & 198.5 \\
Iodine value (mg iodine/g) & 227 \\
Free fatty acid & 3.0855 \\
Viscosity $\left(\mathrm{mm}^{2} / \mathrm{s}\right)$ & 47 \\
\hline
\end{tabular}

completely miscible, two layers were observed: the upper layer was of methanol and the lower layer was of oil. Reaction mixture was taken in conical flask and it is placed into water bath of Toshniwal Ultrasonic Cleaner (30 kHz frequency), which was used for ultrasonication, after achieving desired reaction temperature of water in ultrasonic cleaner. During reaction under ultrasound irradiation, no external stirring is provided. The mixing took place due to the effect of ultrasound wave mechanism in water-bath. The reaction mixture was kept for the predecided reaction time under ultrasonic effect and then taken for centrifugation at 1800 to $2000 \mathrm{rpm}$ using laboratory centrifuge. Later the mixture was allowed to settle in separating funnel to get two separate layers of biodiesel and glycerine. Separation of biodiesel and glycerine was done using a separating funnel. Water wash was given to the separated biodiesel to remove water soluble impurities and then dried to remove moisture by putting under calcination.

\section{Results and Discussion}

\subsection{Properties of Biodiesel}

Biodiesel produced was analyzed and compared with the fuel properties of petro-diesel as per ASTM Standards (Table 2). The Jatropha oil, however, was found to have much higher values of fuel properties, especially kinematic viscosity (Table 1), restricting the direct use as a fuel in diesel engine. After transesterification, the kinematic viscosity value reduced to permissible limit. The flash points were in a limit of safe storage and handling conditions. The pour point and cloud points were little higher than petro-diesel. This might be due to presence of wax, which begins to crystallize with the decrease in temperature. This problem could be solved by using blend of biodiesel with petro-diesel.

\subsection{Influence of Reaction Parameters}

Experiments were carried out by changing different process parameters.

Table 2. Comparison fuel properties of petro-diesel, biodiesel and ASTM D6751.

\begin{tabular}{cccc}
\hline Fuel properties & Petro-diesel & $\begin{array}{c}\text { Biodiesel } \\
(\mathrm{B} 100)\end{array}$ & ASTM D6751 \\
\hline $\begin{array}{c}\text { Specific gravity at } \\
15^{\circ} \mathrm{C}\end{array}$ & 0.846 & 0.875 & $0.86-0.90$ \\
$\begin{array}{c}\text { Kinematic viscosity } \\
\left(\mathrm{mm}^{2} / \mathrm{s}\right) \text { at } 40^{\circ} \mathrm{C}\end{array}$ & $1.9-6.0$ & 4.756 & $4-6$ \\
Flash Point $\left({ }^{\circ} \mathrm{C}\right)$ & Minimum 130 & 165 & $100-170$ \\
Cloud Point $\left({ }^{\circ} \mathrm{C}\right)$ & -5 & -3 & -3 to 12 \\
Pour Point $\left({ }^{\circ} \mathrm{C}\right)$ & -10 & -8 & -15 to 10 \\
Cetane number & Minimum 47 & 54.25 & $48-65$ \\
\hline
\end{tabular}




\subsubsection{Methanol to Oil Molar Ratio}

Stoichiometrically, the methanolysis of Jatropha oil requires three moles of methanol for each mole of oil. Since, transesterification of triglycerides is reversible reaction; excess methanol is required to shift the equilibrium towards the direction of ester formation. As can be seen from Figure 2 (at $303 \mathrm{~K}$ ) and Figure 3 (at $323 \mathrm{~K}$ ), the maximum conversion was achieved at methanol to oil molar ratio 9:1. It is comparable to the work carried out by H. D. Hanh et al. [5] obtained 90\% conversion using methanol as an alcohol with triolein oil to alcohol molar ratio of 1:6 and $\mathrm{KOH}$ as a catalyst. D. Kumar et. al. [6] have obtained above 98\% yield using 1:9 Jatropha oil to methanol molar ratio and heterogeneous solid catalyst used was $\mathrm{Na} / \mathrm{SiO}_{2}$. Present study shows that with molar ratio of oil to methanol of 1:12, maximum conversion was achieved in 30 minutes only and after that it almost a constant over an extended reaction time. Molar ration of 1:3 and 1:6 are not showing good results. One of the reasons for the same may be the predominance of esterification reaction at the initial phase, to transesterify the FFA present in the Jatropha oil, of transesterification which can consume methanol present in the reaction mixture and hence, the amount of methanol available for transesterification may not be sufficient to drive the reaction forward for longer time.

\subsubsection{Amount of Catalyst}

Effect of variation of amount of catalyst on conversion was also studied. Catalyst amount was varied in the range of $0.5 \%$ to $2.5 \%$ (wt/wt of the oil taken). As shown in Figure 4, the conversion increased firstly with the increase of catalyst amount from $0.5 \%$ to $1.5 \%$. But, with further increase in the catalyst amount from $1.5 \%$ to $2.5 \%$, the conversion decreased due to soap formation. D. Kumar et al. [6] obtained their best result at 3\% wt\% catalyst amount which is higher than the present study. Separation of heterogeneous catalyst is adding one more stage in the process presented by D. Kumar. H. D. Hanh et al. [5] obtained about $90 \%$ conversion with $1 \% \mathrm{wt} \%$ of $\mathrm{NaOH}$ catalyst. The conversion obtained by them is less than what obtained in present study using same amount of catalyst.

\subsubsection{Reaction Time and Temperature}

Figure 5 shows the conversion versus reaction time at different temperatures. It could be seen from the plot that the conversion increased in the reaction time range of 10 to 45 minutes with the increase in temperature, and there after remained nearly constant as a representative of a nearby equilibrium conversion. The nearly equilibrium conversion was found to be about $93.5 \%$ at 45 minutes of reaction time. Effect of reaction temperature is not studied by D. Kumar et al. [6] using heterogeneous solid

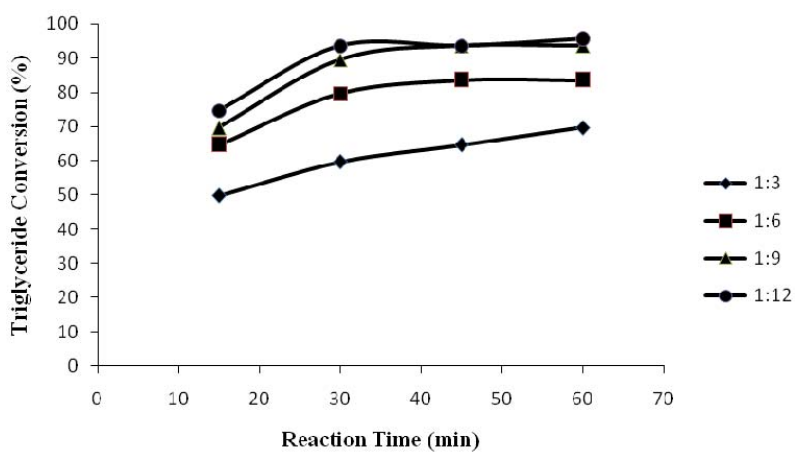

Figure 2. Effect of molar ratio on conversion of triglyceride at $303 \mathrm{~K}$. Reaction conditions: Jatropha oil $50 \mathrm{~g}$, catalyst amount $1 \%$.

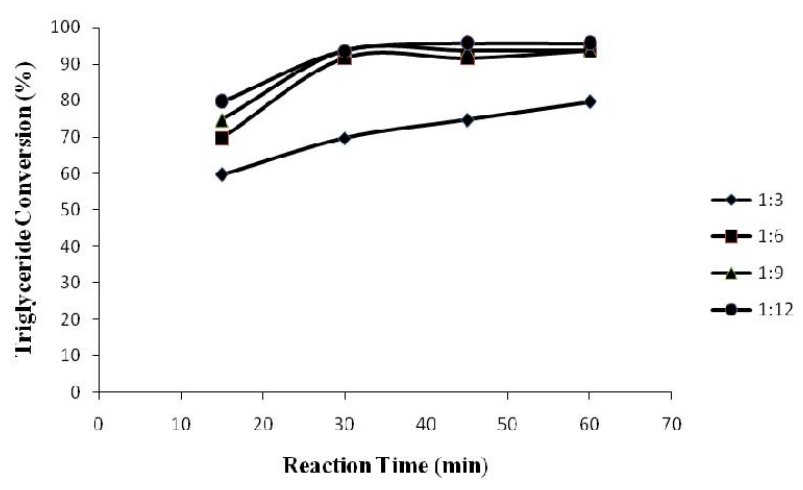

Figure 3. Effect of molar ratio on conversion of triglyceride at $323 \mathrm{~K}$. Reaction conditions: Jatropha oil $50 \mathrm{~g}$, catalyst amount $1 \%$.

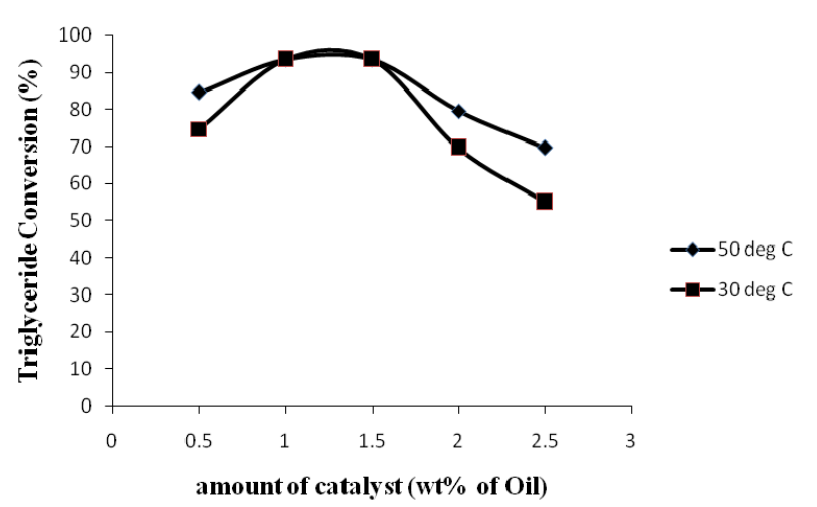

Figure 4. Effect of amount of catalyst on triglyceride conversion. Reaction conditions: Jatropha oil 50 g, Oil to Methanol Molar Ratio 1:9, Reaction time $30 \mathrm{~min}$ for $323 \mathrm{~K}$ and $45 \mathrm{~min}$ for $303 \mathrm{~K}$.

catalyst but results published (Table 5) for feedstocks other than Jatropha oil shows that reaction time obtained in present study is at par with other published results.

\section{Reaction Kinetics}

Experiments were carried out at three different tempera- 


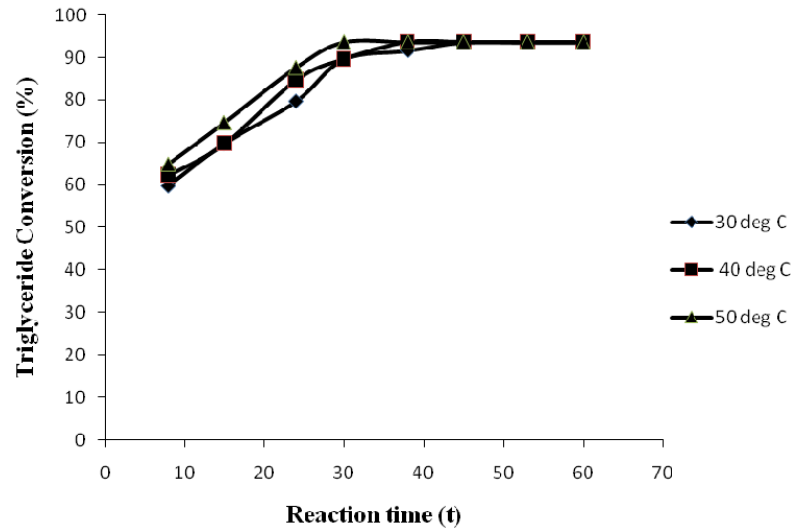

Figure 5. Effect of reaction temperature on triglyceride conversion. Reaction conditions: Jatropha oil $\mathbf{5 0}$ g, catalyst amount 1\%, Oil to Methanol Molar Ratio 1:9.

tures $303 \mathrm{~K}, 313 \mathrm{~K}$ and $323 \mathrm{~K}$. It could be seen from Figure 5 that with increase in reaction temperature conversion also increased. The overall rate equation $(k)$ can be found using (1) for first order reaction and (2) for second order reaction.

$$
\begin{gathered}
k=-\ln \left(1-X_{A}\right) / \mathrm{t} \\
k C_{A o}=-\ln \left(X_{A} /\left(1-X_{A}\right)\right) / \mathrm{t}
\end{gathered}
$$

where $X_{A}$ is the conversion of triglyceride.

The experimental data collected at $303 \mathrm{~K}, 313 \mathrm{~K}$ and $323 \mathrm{~K}$ were tested for $1^{\text {st }}$ order kinetics (Figures 6 to 8 and Table 3) and $2^{\text {nd }}$ order kinetics (Figures 9 to 11, and Table 3). The experimental data fitted well for $1^{\text {st }}$ order kinetics. The rate data collected were subjected to Arhenius equation as follows:

$$
\begin{gathered}
k=k_{0} * \exp (-E / R T) \\
\ln k=(-E / R T)+\ln k_{0}
\end{gathered}
$$

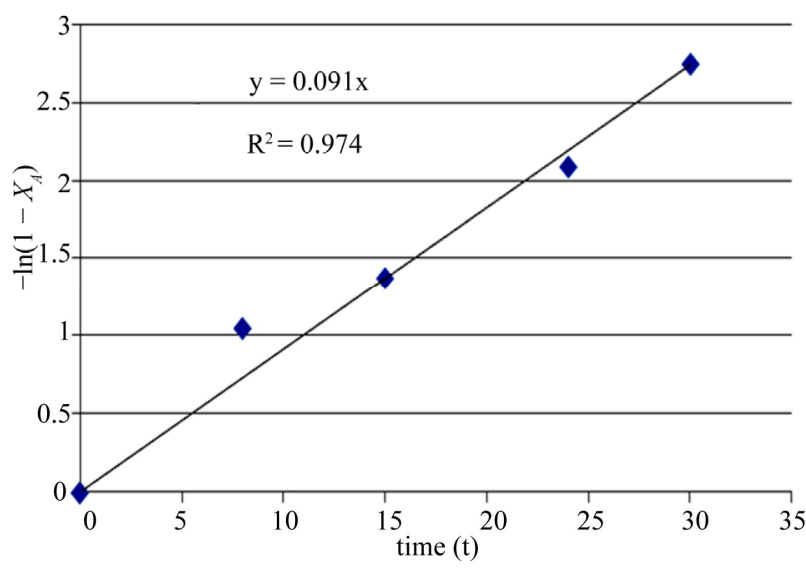

Figure 6. Plot of $-\ln \left(1-X_{A}\right)$ vs time, $t$ (minutes) at $323 \mathrm{~K}$ assuming first order reaction. Rate constant $k=0.091 \mathrm{~min}^{-1}$. Oil: Methanol $=1: 9, \mathrm{NaOH}=1 \% \mathrm{wt} \%$.
Table 3. Reaction rate constant $k\left(\mathrm{~min}^{-1}\right)$ at different temperatures for first order and second order reactions assumption, respectively.

\begin{tabular}{cccc}
\hline $\begin{array}{c}\text { Order of } \\
\text { Reaction } \\
\text { (Assumed) }\end{array}$ & $\begin{array}{c}\text { Reaction } \\
\text { Temperature, } \\
\mathrm{K}\end{array}$ & Rate Constant, $k$ & $\mathrm{R}^{2}$ \\
\hline First & 303 & $0.06 \mathrm{~min}^{-1}$ & 0.944 \\
& 313 & $0.075 \mathrm{~min}^{-1}$ & 0.967 \\
& 323 & $0.091 \mathrm{~min}^{-1}$ & 0.974 \\
Second & 303 & $353.10 \mathrm{ml} / \mathrm{mol}^{*} \mathrm{~min}^{-1}$ & 0.807 \\
& 313 & $447.96 \mathrm{ml} / \mathrm{mol}^{*} \mathrm{~min}^{-1}$ & 0.807 \\
& 323 & $534.92 \mathrm{ml} / \mathrm{mol}^{*} \mathrm{~min}^{-1}$ & 0.807 \\
\hline
\end{tabular}

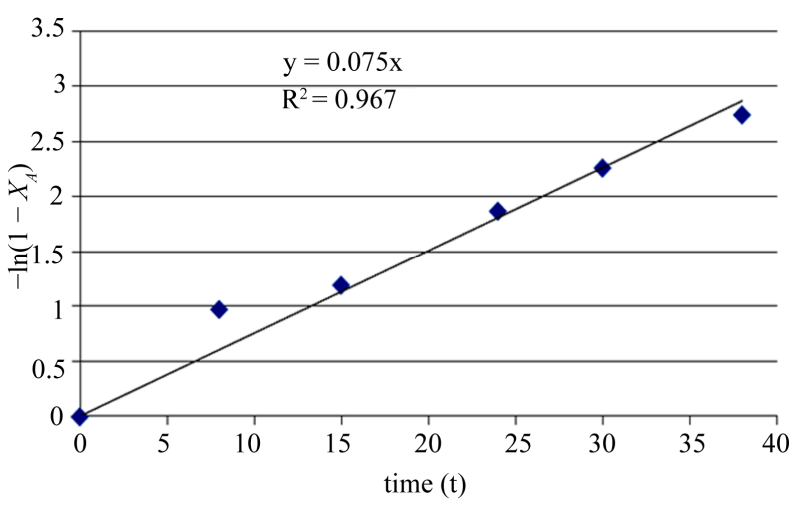

Figure 7. Plot of $-\ln \left(1-X_{A}\right)$ vs time, $t$ (minutes) at $313 \mathrm{~K}$ assuming first order reaction. Rate constant $k=0.075 \mathbf{~ m i n}^{-1}$. Oil: Methanol $=1: 9, \mathrm{NaOH}=1 \%$ wt $\%$.

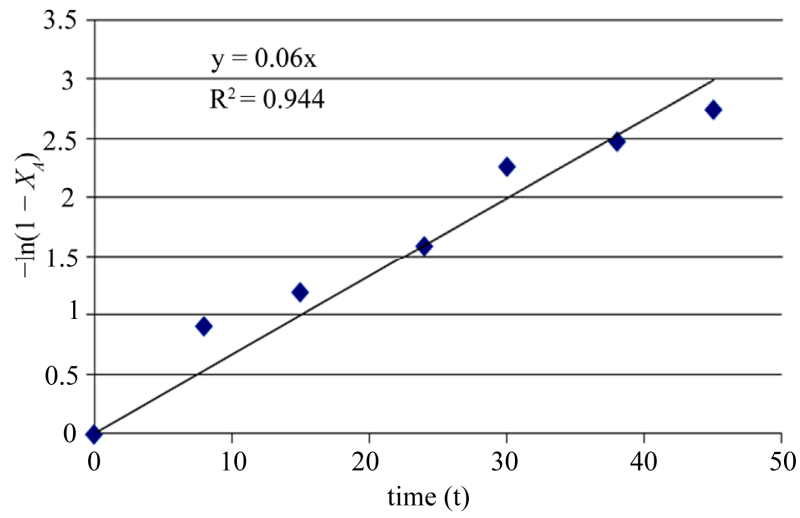

Figure 8. Plot of $-\ln \left(1-X_{A}\right)$ vs time, $t$ (minutes) at $303 \mathrm{~K}$ assuming first order reaction. Rate constant $k=0.06 \mathrm{~min}^{-1}$. Oil: Methanol $=1: 9, \mathrm{NaOH}=1 \% \mathrm{wt} \%$.

where, $E$ is activation energy, $R$ is the gas constant ( $/ \mathrm{mol}-\mathrm{K}), T$ is an absolute temperature, and $k_{0}$ is a frequency factor.

From the plot of $\ln k$ versus $1 / \mathrm{T}$ (Figure 12, Table 4), $-\mathrm{E} / \mathrm{R}=$ Slope of the graph $=-2039$. Therefore, Activation energy $E=2039 \times 1.987=4051.49 \mathrm{cal} / \mathrm{mol}$, and

$$
\ln k_{0}=3.918
$$$$
k_{0}=50.30
$$ 
Table 4. Database for determination of activation energy.

\begin{tabular}{cccc}
\hline $\begin{array}{c}\text { Reaction } \\
\text { Temperature, } T \\
(\mathrm{~K})\end{array}$ & $1 / T$ & $\begin{array}{c}\text { Rate Constant, } k \\
\left(\mathrm{~min}^{-1}\right)\end{array}$ & $\ln k$ \\
\hline 303 & 0.0033 & $0.06 \mathrm{~min}^{-1}$ & -2.81341 \\
313 & 0.003195 & 0.075 & -2.59027 \\
323 & 0.003096 & 0.091 & -2.3969 \\
\hline
\end{tabular}

Rate equation derived from the above data of activation energy for the ultrasound assisted transesterification reaction is:

$$
-r_{A}=\mathrm{d} X_{A} / \mathrm{d} t=k C_{A o}\left(1-X_{A}\right)
$$

where, $k=k_{0} * \exp (-E / R T)$

Substituting the values of $k_{0}, E$ and $R$ in (3) and also substituting (3) in (5) the rate equation for the reaction is:

$-r_{A}=50.30 * C_{A o} * \exp (-4051.49 /(1.987 * T)) *\left(1-X_{A}\right)$

\section{Conclusions}

Ultrasound assisted transesterification reaction for the production of biodiesel was found to be very promising from the results obtained. The optimum conditions for the production of biodiesel from Jatropha oil under the full ultrasound condition were molar ratio of oil to methanol of 1:9 with $\mathrm{NaOH}$ concentration of $1 \mathrm{wt} \%$ and reaction time of $30 \mathrm{~min}$. Increasing reaction time and temperature as well as the molar ratio contributes to high conversion of triglyceride. The transesterification of Jatropha oil under ultrasound condition provides a possibility for producing cheap alternative fuels, which will reduce pollution and protect the environment. The conversion is comparable to the results reported by C. Stavarache et al. [7]

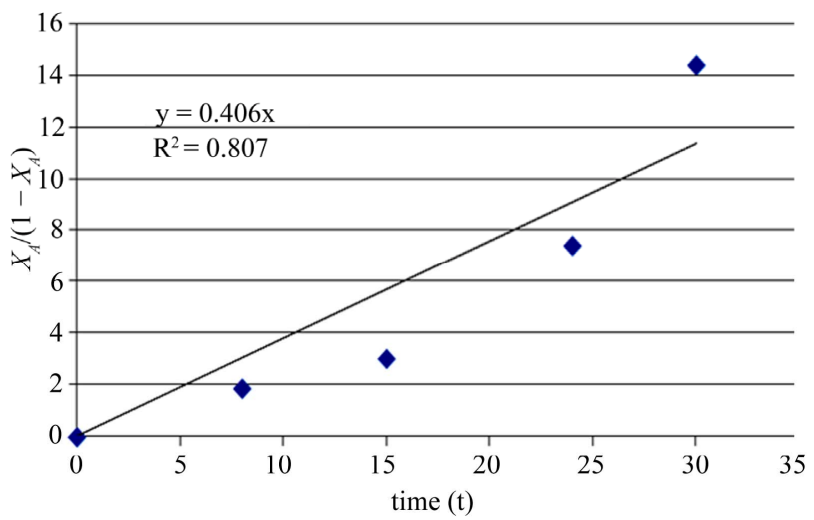

Figure 9. Plot of $-\ln \left[X_{A} /\left(1-X_{A}\right)\right]$ vs time, $t$ (minutes) at 323 $\mathrm{K}$ assuming second order reaction. $C_{A o}=0.00075899 \mathrm{~mol} / \mathrm{ml}$. Rate constant $\mathrm{k}=534.92 \mathrm{ml} / \mathrm{mol}^{*} \mathrm{~min}^{-1}$. Oil: Methanol = 1:9, $\mathrm{NaOH}=1 \% \mathrm{wt} \%$.

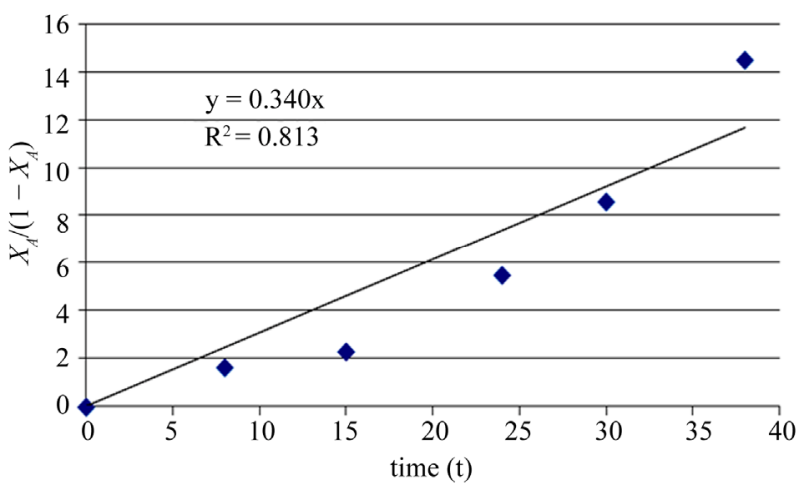

Figure 10. Plot of $-\ln \left[X_{A} /\left(1-X_{A}\right)\right]$ vs time, $t$ (minutes) at 313 $\mathrm{K}$ assuming second order reaction. $C_{A o}=0.00075899 \mathrm{~mol} / \mathrm{ml}$. Rate constant $\mathrm{k}=447.96 \mathrm{ml} / \mathrm{mol}^{*} \mathrm{~min}^{-1}$. Oil: Methanol = 1:9, $\mathrm{NaOH}=1 \% \mathrm{wt} \%$.

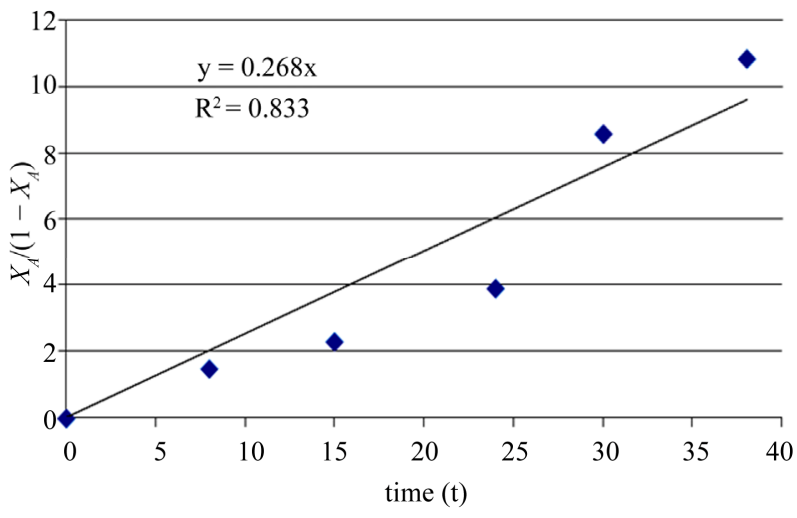

Figure 11. Plot of $-\ln \left[X_{A} /\left(1-X_{A}\right)\right]$ vs time, $t$ (minutes) at 303 $\mathrm{K}$ assuming second order reaction. $C_{A o}=0.00075899 \mathrm{~mol} / \mathrm{ml}$. Rate constant $\mathrm{k}=353.10 \mathrm{ml} / \mathrm{mol}^{*} \mathrm{~min}^{-1}$. Oil: Methanol = 1:9, $\mathrm{NaOH}=1 \%$ wt $\%$.

$1 / \mathrm{T}$

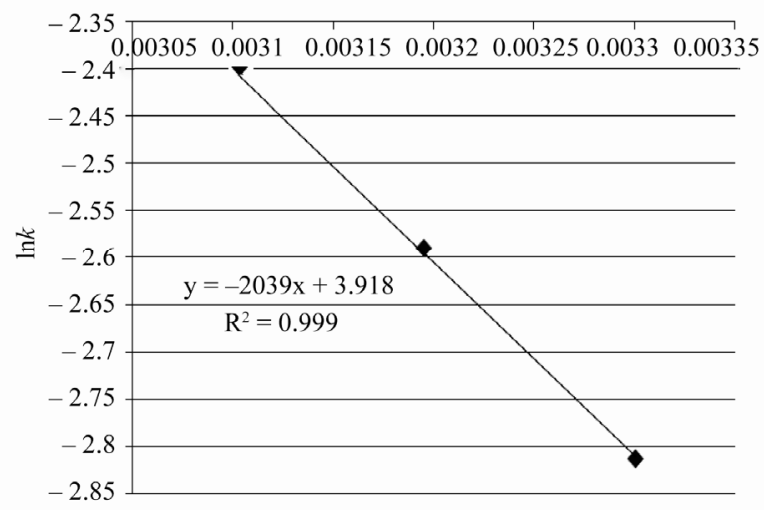

Figure 12. Plot of $\ln k$ vs $1 / T$ for the transesterification reaction under ultrasound conditions.

where they used n-propanol as a solvent which is higher molecular weight alcohol compared to methanol used in this study. Other reported result was for the feedstock 
Table 5. Comparative study of ultrasound assisted transesterification [8].

\begin{tabular}{|c|c|c|c|c|c|c|c|c|c|c|}
\hline $\begin{array}{l}\text { Oil/Tri- } \\
\text { olein }\end{array}$ & Catalyst & $\begin{array}{c}\text { Catalyst } \\
\text { wt } \% \text { of } \\
\text { oil }\end{array}$ & Alcohol & $\begin{array}{c}\text { Oil to } \\
\text { Alcohol } \\
\text { Molar } \\
\text { Ratio }\end{array}$ & $\begin{array}{l}\text { Ultrasonic } \\
\text { Frequency }\end{array}$ & $\begin{array}{l}\text { Source of } \\
\text { Ultrasound }\end{array}$ & $\begin{array}{c}\text { Reaction } \\
\text { Conditions }\end{array}$ & $\begin{array}{c}\text { Ester } \\
\text { Yield, \% }\end{array}$ & $\begin{array}{c}\text { Ester } \\
\text { Conver- } \\
\text { sion, \% }\end{array}$ & Ref. \\
\hline Triolein & $\mathrm{KOH}$ & 1 & Methanol & $1: 6$ & $40 \mathrm{kHz}$ & $\begin{array}{l}\text { Ultrasonic Cleaner } \\
\qquad(1200 \mathrm{~W})\end{array}$ & $\begin{array}{c}25^{\circ} \mathrm{C} \\
10 \mathrm{~min} \\
25^{\circ} \mathrm{C}\end{array}$ & - & $>90$ & [5] \\
\hline NA & $\mathrm{NaOH}$ & 0.5 & n-Propanol & $1: 6$ & $\begin{array}{l}28 \mathrm{kHz} \\
40 \mathrm{kHz}\end{array}$ & $\begin{array}{l}\text { Ultrasonic Cleaner } \\
\qquad(1200 \mathrm{~W})\end{array}$ & $\begin{array}{c}20 \mathrm{~min} \\
25^{\circ} \mathrm{C} \text {, } \\
20 \mathrm{~min}\end{array}$ & $\begin{array}{l}92 \\
88\end{array}$ & - & [7] \\
\hline Triolein & $\mathrm{NaOH}$ & 1 & Ethanol & $1: 6$ & $40 \mathrm{kHz}$ & $\begin{array}{l}\text { Ultrasonic Cleaner } \\
\qquad(1200 \mathrm{~W})\end{array}$ & $\begin{aligned} & 25^{\circ} \mathrm{C} \\
< & 20 \mathrm{~min}\end{aligned}$ & - & 98 & [9] \\
\hline $\begin{array}{c}\text { Soybean } \\
\text { frying } \\
\text { Oil }\end{array}$ & $\mathrm{NaOH}$ & 1.5 & Methanol & NA & $24 \mathrm{kHz}$ & $\begin{array}{l}\text { Ultrasonicator } \\
\text { (200 W) }\end{array}$ & $\begin{array}{c}60^{\circ} \mathrm{C} \\
20 \mathrm{~min}\end{array}$ & 97 & - & {$[10]$} \\
\hline Fish Oil & $\mathrm{C}_{2} \mathrm{H}_{5} \mathrm{ONa}$ & 0.8 & Ethanol & $1: 6$ & $20 \mathrm{kHz}$ & Ultrasonic Probe & $\begin{array}{l}60^{\circ} \mathrm{C} \\
60 \min \end{array}$ & 98.2 & - & [8] \\
\hline
\end{tabular}

of soybean frying oil [10]. The present study compares favourably with the results reported in literature. Other comparable published results of different researchers are presented in Table 5. Since, the process seems economic; the economic study is to be carried out.

\section{Acknowledgements}

The authors thank the authorities of the Nirma Univesity, Ahmedabad for supporting the investigation.

\section{References}

[1] A. P. Vyas, N. Subrahmanyam and P. A. Patel, "Production of Biodiesel through Transesterification of Jatropha Oil Using $\mathrm{KNO}_{3} / \mathrm{Al}_{2} \mathrm{O}_{3}$ Solid Catalyst," Fuel, Vol. 88, No. 4, 2009, pp. 625-628. doi:10.1016/j.fuel.2008.10.033

[2] A. Kalva, T. Sivasankar and V. S. Moholkar, "Physical Mechanism of Ultrasound-Assisted Synthesis of Biodiesel," Industrial \& Engineering Chemistry Research, Vol. 48, No. 1, 2009, pp. 534-544. doi:10.1021/ie800269g

[3] A. K. Singh, S. D. Fernando and R. Hernandez, "BaseCatalyzed Fast Transesterification of Soybean Oil Using Ultrasonication,” Energy \& Fuels, Vol. 21, No. 2, 2007, pp. 1161-1164. doi:10.1021/ef060507g

[4] A. P. Vyas, J. L. Verma and N. Subrahmanyam, "A Review on FAME Production Processes,” Fuel, Vol. 89, No. 1, 2010, pp. 1-9. doi:10.1016/j.fuel.2009.08.014
[5] H. D. Hanh, N. T. Dong, K. Okitsu, R. Nishimura and M. Yasuaki, "Effects of Molar Ratio, Catalyst Concentration and Temperature on Transesterification of Triolein with Ethanol under Ultrasonic Irradiation,” Journal of the Japan Petroleum Institute, Vol. 50, No. 4, 2007, pp. 195199. doi:10.1627/jpi.50.195

[6] D. Kumar, G. Kumar and C. P. P. Singh, "UltrasonicAssisted Transesterification of Jatropha curcus Oil Using Solid Catalyst, $\mathrm{Na} / \mathrm{SiO}_{2}$," Ultrasonics Sonochemistry, Vol. 17, No. 5, June 2010, pp. 839-844. doi:10.1016/j.ultsonch.2010.03.001

[7] C. Stavarache, M. Vinatoru, R. Nishimura and Y. Maeda, "Fatty Acids Methyl Esters from Vegetable Oil by Means of Ultrasonic Energy,” Ultrasonics Sonochemistry, Vol. 12, No. 5, 2005, pp. 367-372. doi:10.1016/j.ultsonch.2004.04.001

[8] R. E. Armenta, M. Vinatoru, A. M. Burja, J. A. Kralovec and C. J. Barrow, "Transesterification of Fish Oil to Produce Fatty Acid Ethyl Esters Using Ultrasonic Energy," Journal of the American Oil Chemists' Society, Vol. 84, No. 11, 2007, pp. 1045-1052.

[9] H. D. Hanh, N. T. Dong, K. Okitsu, R. Nishimura and M. Yasuaki, "Biodiesel Production through Transesterification of Triolein with Various Alcohols in an Ultrasonic Field,” Renewable Energy, Vol. 34, No. 3, 2009, pp. 766768. doi:10.1016/j.renene.2008.04.007

[10] K. G. Georgogianni, M. G. Kontominas, E. Tegou, D. Avlonitis and V. Gergis, "Biodiesel Production: Reaction and Process Parameters of Alkali-Catalyzed Transesterification of Waste Frying Oils,” Energy \& Fuels, Vol. 21, No. 5, 2007, pp. 3023-3027. doi:10.1021/ef070102b 